\title{
Design, Fabrication and in Vitro Evaluation of Metformin HCl Matrix Tablets for Treatment of Diabetes Mellitus
}

\author{
Shyamos hree Bas u Ghos h*, Sumit Mukhe rjee \\ NSHM College of Pharmaceutical Technology, NSHM Knowledge Campus, Kolkata, West Bengal University of Technology, 700053, \\ Kolkata
}

\begin{abstract}
Diabetes mellitus is a growing problem in today's world. The aim of the present study was to design and develop matrix tablets of metformin $\mathrm{HCl}(\mathrm{MTH})$ with hydroxy propyl methyl cellu lose K15M (HPMCK15M) and ethyl cellu lose (EC) in different ratios. The prepared tablets were evaluated in terms of hardness, friability, drug content and in vitro drug release profiles. It was observed that formulation with HPMC and EC in a ratio of 2:1 gave reproducible results in all aspects and showed sustained drug release profile for $12 \mathrm{~h}$.
\end{abstract}

Keywords Diabetes Mellitus, Matrix Tablet, Metformin Hcl

\section{Introduction}

Diabetes mellitus is rapidly becoming a serious threat to human health. According to World Health Organization estimates, number of people with diabetes worldwide, in 2000, was 171 million, which is likely to increase at least 366 million by $2030[1]$. This increase will be most noticeable in developing countries, where the number of people with diabetes is expected to increase from 84 million to 228 million. According to the WHO, Southeast Asia and the Western Pacific region are at the forefront of the current diabetes epidemic, with India and China facing the greatest challenges. In these countries, the incidence and prevalence of type 2 diabetes among children are also increasing at an alarming rate, with potentially devastating consequences[2]. Metformin $\mathrm{HCl}(\mathrm{MTH})$ is an anti-diabetic drug which is prescribed for the treatment of non-insulin dependent diabetes mellitus [3]. In addition, it has a favourable action on cardiovascular risk factors, which are often present in these individuals. It helps in maintaining diet-induced weight loss and lowers fasting plasma insulin concentrations, total and low density lipoprotein-cholesterol, and free fatty acids. These effects make MTH a first-line agent for the prevention of type 2 diabetes [4]. The average MTH elimination half-life in plas ma is $6.2 \mathrm{~h}$ and its peak plasma concentration $\left(\mathrm{C}_{\max }\right)$ is achieved within 4 to 8 hours with extended-release formulations. In spite of its favourable clinical response and lack of significant drawbacks, chronic therapy with MTH suffers from certain specific problems of which, the most

* Corresponding author:

shyamoshree@gmail.com (Shyamoshree Basu Ghosh)

Published online at http://journal.sapub.org/scit

Copyright (C) 2012 Scientific \& Academic Publishing. All Rights Reserved prominent being the high dose (1.5-2.0 g/day), low bioavailability $(60 \%)$, high incidence of gastrointestinal (GI) tract side effects ( $30 \%$ cas es) and decreased absorption of the drug with food that delays time to reach maximum drug concentration in blood $\left(\mathrm{t}_{\max }\right)$ by half-an-hour[5,6]. Thus there exists a potential for MTH to be used in the sustained release formulation tablets. The primary benefit of sustained release preparations of MTH compared to an immediate release formulation is that a more uniform maintenance of blood plasma active concentration can be achieved, potentially avoiding undesirable peaks and troughs associated with multiple immediate release preparation applications.

Hydroxy propyl methyl cellulose (HPMC) is the most commonly and successfully used hydrophilic polymer for the preparation of oral controlled drug delivery systems [7]. Upon contact with the gastrointestinal fluid, HPMC swells, gels, and finally dissolves slowly[8]. The gel becomes a viscous layer acting as a protective barrier to both the influx of water and the efflux of the drug insolation. Volume proportion of the polymer in the formulation increases, the gel formed is more likely to diminish the diffusion of the drug and delay the erosion of the matrix. The dissolution can be either disentanglement or diffusion controlled depending on the molecular weight and thickness of the coating layer. The rates of polymer swelling, dissolution and drug release are found to increase with both increasing levels of drug loading or with use of lower viscosity grades of HPMC. Additionally, use of hydrophobic polymers significantly slows the drug release. So in the present investigation, an attempt has been made to formulate the extended - release matrix tablets of MTH using hydrophilic matrix material HPMC K15 M in combination with hydrophobic ethyl cellu lose. 
The present study focuses at the development and optimization of an extended release formulation (matrix tablet) of $\mathrm{MTH} \mathrm{HCl}$ for the treatment of diabetes mellitus.

\section{Materials and Methods}

Metformin $\mathrm{HCl}$ was obtained as a gift sample from Ranbaxy Laboratories Limited, India. Hydroxy propyl methyl cellu lose $\mathrm{K} 15 \mathrm{M}$ was obtained as a gift sample from Colorcon Asia Pvt Ltd. Ethyl cellulose, Micro crystalline cellu lose, Magnesium stearate and talc were purchased from S.D. Fine Chemicals.

\subsection{Preparation of the Matrix Tablet}

Matrix tablets were prepared by non-aqueous wet granulation method. The composition of various formulations is given in Table 1. MTH HCL, HPMC K15M, EC, MCC were weighed accurately and individually passed through a 60 mesh and the mixture was passed through sieve mesh No. 40. The powdered ingredients were compressed into tablets on a 10-station mini rotary tableting machine with 12-mm round punches at a constant rotational speed of $72 \mathrm{rpm}$.

Table 1. Composition of the tablets

\begin{tabular}{|c|c|c|c|c|c|}
\hline $\begin{array}{l}\text { Ingredients } \\
\text { (mg) }\end{array}$ & F1 & F2 & F3 & F4 & F5 \\
\hline Metformin $\mathrm{HCl}$ & 500 & 500 & 500 & 500 & 500 \\
\hline $\begin{array}{r}\text { HPMC } \\
\text { K15M }\end{array}$ & 300 & 200 & 175 & 150 & - \\
\hline Ethyl cellulose & - & 100 & 125 & 150 & 300 \\
\hline $\begin{array}{l}\text { Microcrystalline } \\
\text { cellulose }\end{array}$ & 190 & 190 & 190 & 190 & 190 \\
\hline $\begin{array}{l}\text { Magnesium } \\
\text { Stearate }\end{array}$ & 5 & 5 & 5 & 5 & 5 \\
\hline Talc & 5 & 5 & 5 & 5 & 5 \\
\hline $\begin{array}{l}\text { Total } \\
\text { weight } \\
(\mathrm{mg})\end{array}$ & & 1000 & 1000 & 1000 & 1000 \\
\hline
\end{tabular}

\subsection{Physicochemical Evaluation of Metformin $\mathrm{HCl}$ Matrix Tablets}

\subsubsection{Hardness Test}

Hardness of 6 tablets was determined using a hardness tester (EH- 01, Digital hardness tester, Electrolab, India). Hardness values were reported in kilograms $\left(\mathrm{kg} / \mathrm{cm}^{2}\right)[8]$. Mean and SD were calcu lated.

\subsubsection{Friability Test}

20 tablets were weighed and placed in a friabilator (EF-2 Friabilator, Electrolab, India) and subjected to 100 rotations for $4 \mathrm{~min}$. The tablets were then dedusted and reweighed. The friability was calculated as the percentage weight $\operatorname{loss}[9]$.

\subsubsection{Weight variation}

20 tablets of each formulation were weighed using an electronic balance. Weight values were reported in milligrams. Mean and SD were calculated[10].

\subsubsection{Drug content}

To determine drug content, 6 tablets of each formulation were weighed and crushed to powder with mortar and pestle. $300 \mathrm{mg}$ of powder was taken and dis solved with appropriate amount of methanol with the aid of sonicator. After which the solution was filtered through filter paper. The total amount of the drug in the tablet was analysed after appropriate dilution of test solution by using UV spectrophotometer (UV-VIS Spectrophotometer, Shimadzu, Japan) at $233 \mathrm{~nm}$ against the reference solution with suitable dilution.

\subsubsection{In Vitro Drug Release Study}

In vitro drug release study of each formulation was determined using the USP Type II Dissolution apparatus (Labindia Instruments, India) where $900 \mathrm{ml}$ of phosphate buffer saline $(\mathrm{pH}$ 6.8) were used as dissolution media and maintained at $37 \pm 0.50{ }^{\circ} \mathrm{C}$ at $50 \mathrm{rpm}$. The release rate experiments were conducted in $0.1 \mathrm{~N} \mathrm{HCl}$ for $2 \mathrm{~h}$ and thereafter in phosphate buffer saline of $\mathrm{pH} 7.4$ for $12 \mathrm{~h}$. Aliquots of $1 \mathrm{ml}$ were withdrawn at fixed intervals and replaced with fresh media. Then samples were analysed in the same spectrophotometer at $233 \mathrm{~nm}$, keeping the dissolution media as reference sample.

In order to determine the release model which best describes the pattern of drug release, the in vitro release data were fitted to zero order, first order and diffusion controlled release mechanis ms according to the simplified Higuchi model[11]. The selection of a preferred mechanism was based on the correlation coefficient (r) for the parameters studied, where the highest correlation coefficient is preferred for the selection of mechanis $m$ of release. Data analysis was carried out using the following Korsmeyer and Peppas[12]

$$
\mathrm{Mt} / \mathrm{M} \infty=\mathrm{K} \cdot \mathrm{t}^{\mathrm{n}}
$$

where $\mathrm{Mt} / \mathrm{M}_{\infty}$ is the fraction released by the drug at time $\mathrm{t}$, $\mathrm{K}$ is a constant incorporating structural and geometric characteristic and $\mathrm{n}$ is the release exponent characteristic for the drug transport mechanism. When $\mathrm{n}=0.5$ fickian diffusion is observed and the release rate in dependent on $\mathrm{t}$, while $0.5<\mathrm{n}<1.0$ indicate anomalous (non-fickian) transport and when $\mathrm{n}=1$ and the release model is zero order.

\section{Results and discussion}

Tablets of different formu lations were subjected to various evaluation tests, such as weight variation, drug content, hardness, friability, and in vitro dissolution study. The average weight variation of 20 tablets of each formulation 
was less than $\pm 5 \%$. Drug content was found to be uniform among different batches of the tablets and ranged from $98.00 \pm 0.34$ to $99.77 \pm 0.53 \%$. The hardness and percentage friability of the tablets of all batches ranged from $4.50 \pm 0.51$ to $5.50 \pm 0.72 \mathrm{~kg} / \mathrm{cm}^{2}$ and $0.62 \%$ to $0.70 \%$, respectively (Table 2). Tablets of all formulations showed uniform thickness. In a weight variation test, the pharmacopoeial limit for the percentage deviation for tablets of more than $250 \mathrm{mg}$ is $\pm 5 \%$. The average percentage deviation of all tablet formulations was found to be within the above limit, and hence all formulations passed the test for uniformity of weight as per official requirements[10].

Conventionally, the compressed tablets that lose less than $1 \%$ of their weight are generally considered acceptable. In the present study, the percentage friability for all the formulations was below $1 \%$, indicating that the friability is within the prescribed limits. All the tablet formulations showed acceptable pharmacopoeial properties and complied with the prescribed specifications for weight variation, drug content, hardness, and friability.

Table 2 contains a summary of the above parameters measured for five different formulations F1-F5 (corresponding compositions - see Table 1)

Table 2. Values Of Thickness, Weight, Friability, Hardness And Drug Content OfTablets with Different Formulations. Data Show Mean \pm SD

\begin{tabular}{ccccc}
\hline $\begin{array}{c}\text { Formulati } \\
\text { on code }\end{array}$ & $\begin{array}{c}\text { Tablet } \\
\text { weight } \\
(\mathrm{mg})\end{array}$ & $\begin{array}{c}\text { Friability } \\
(\%)\end{array}$ & $\begin{array}{c}\text { Hardness } \\
\left(\mathrm{kg} / \mathrm{cm}^{2}\right)\end{array}$ & $\begin{array}{c}\text { Drug } \\
\text { content } \\
(\%)\end{array}$ \\
\hline F1 & $1000 \pm 0.53$ & 0.64 & $4.70 \pm 0.34$ & $99.77 \pm 0.53$ \\
F2 & $1000 \pm 0.45$ & 0.63 & $4.67 \pm 0.44$ & $99.21 \pm 0.65$ \\
F3 & $1000 \pm 0.52$ & 0.70 & $5.50 \pm 0.72$ & $98.00 \pm 0.74$ \\
F4 & $1000 \pm 0.52$ & 0.66 & $4.80 \pm 0.53$ & $98.00 \pm 0.34$ \\
F5 & $1000 \pm 0.54$ & 0.62 & $4.50 \pm 0.51$ & $98.12 \pm 0.45$ \\
\hline
\end{tabular}

Table 3. Release Kinetics Of The Formulations

\begin{tabular}{lcccccc}
\hline $\begin{array}{l}\text { Formu- } \\
\text {-lation } \\
\text { code }\end{array}$ & $\begin{array}{c}\text { Zero } \\
\text { order } \\
\mathrm{r}^{2}\end{array}$ & $\begin{array}{c}\text { First } \\
\text { order } \\
\mathrm{r}^{2}\end{array}$ & $\begin{array}{c}\mathrm{r}^{2} \\
\text { Higuchi }\end{array}$ & $\begin{array}{c}\text { Korsmeyer } \\
\text { Peppas } \\
\mathrm{r}^{2}\end{array}$ & $\mathrm{n}$ & $\begin{array}{c}\text { Hixon } \\
\text { Crowell } \\
\mathrm{r}^{2}\end{array}$ \\
\hline FI & 0.6287 & 0.8255 & 0.9709 & 0.9807 & 0.3455 & 0.5517 \\
F2 & 0.3675 & 0.7814 & 0.9336 & 0.9722 & 0.3850 & 0.4678 \\
F3 & 0.7901 & 0.9388 & 0.9878 & 0.9853 & 0.5528 & 0.5929 \\
F4 & 0.9677 & 0.9816 & 0.9292 & 0.9741 & 0.7109 & 0.7301 \\
F5 & 0.9936 & 0.9937 & 0.8667 & 0.9932 & 0.8280 & 0.8059 \\
\hline
\end{tabular}

Figure 1 shows the in vitro drug release profiles indicating that formu lation $\mathrm{F} 2$ reaches maximum release rate in shorter time and has longest time of stable release with respect to other formulations. Tablets F1 released $100 \%$ of the drug in $6 \mathrm{~h} ; \mathrm{F} 2$ released $40 \%$ of the drug in $1 \mathrm{~h}$ and then release rate was stable for $12 \mathrm{~h}$; F3 released $29 \%$ of the drug in $1 \mathrm{~h}$ and then showed stable release for $12 \mathrm{~h}$; F4 and F5 released 9\% and $5 \%$ of the drug respectively in $1 \mathrm{~h}$ and released $100 \%$ and $71 \%$ in $12 \mathrm{~h}$. Values of $\mathrm{r}^{2}$ of different release kinetic models are displayed in Table 3.

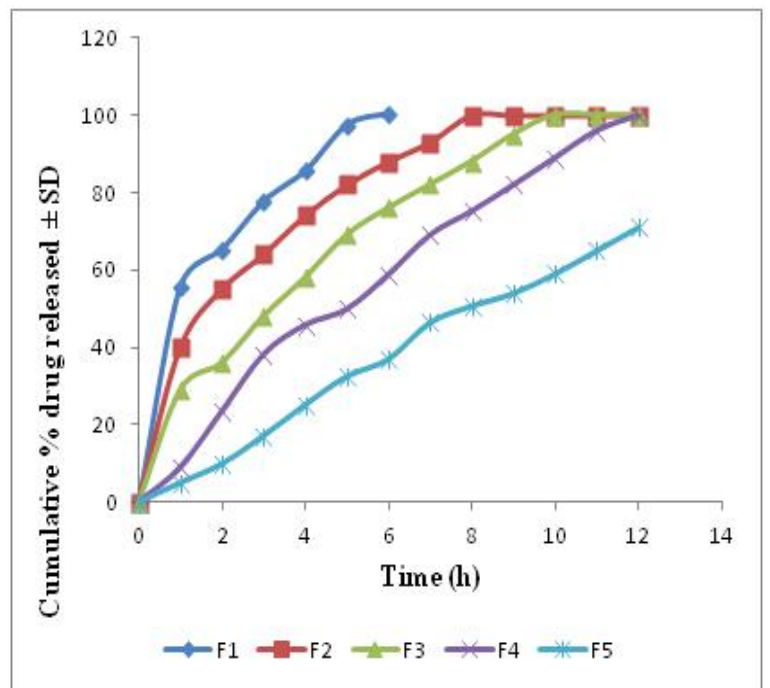

Figure 1. In vitro meformin $\mathrm{HCl}$ release profile from matrix tablets. Data show mean $\pm \mathrm{SD}(\mathrm{n}=6)$

The formulations with a combination of HPMCK 15 and EC with ration of 2:1 were found to be more effective. HPMCK 15 as a hydrophilic material takes up aqueous medium and swells up. On the other hand EC as a hydrophobic material which reduces the penetration of water into the matrix. Thus the polymer matrix beco mes more rig id. The mechanis $m$ of drug release is both dissolution and diffusion controlled. The drug release from the matrix tablet formulations F1, F2, F4, F5 follows Korsmeyer Peppas release kinetics. No burst release is observed. Uniform release is essential to maintain constant drug plasma concentration. It was observed that $\mathrm{F} 3$ formulation follows Higuchi release kinetics[11].

In swellable systems, factors affecting the release kinetics are liquid diffusion rate and polymeric chain relaxation rate. When the liquid diffusion is slower than the relaxation rate of the polymeric chains, the diffusion is Fickian[12], whereas when the relaxation process is very slow compared with the diffusion rate, the case II transport occurs[12]. When liquid diffusion rate and polymer relaxation rate are of the same order of magnitude, anomalous or non-fickian diffusion is observed[12].

The values of $n$ (equation 1) as estimated by linear regression of $\log \mathrm{Mt} / \mathrm{M}_{\infty}$ vs $\log \mathrm{t}$ of different formulations are shown in Table 3[13], the obtained values of $n$ ranges between 0.3455 and 0.8280 for $\mathrm{MTH} \mathrm{HCl}$ release for all the prepared tablets which indicates drug release mechanisms involving a combination of both diffusion and chain relaxation mechanis ms. Therefore, the release of MTH from the prepared tablets is controlled by the swelling of the polymer followed by drug diffusion through the swelled polymer and slow erosion of the tablet.

Specifically, the hydration rate of HPMC increases with an increase in the hydroxypropyl content. The solubility of 
HPMC is $\mathrm{pH}$ independent. In the present study, HPMC K15 was used because it forms a strong viscous gel on contact with aqueous media, which may be useful in controlled delivery of highly water-soluble drugs.

\section{Conclusions}

From the above study it can be inferred that matrix tablet prepared with HPMC and EC in a ratio of 2:1 showed desirable results in terms of hardness, friability, drug content and in vitro drug release profiles.

\section{REFERENCES}

[1] http://www.who.int/diabetes/actionnow/en/DANbooklet.pdf

[2] Giuseppe D, Sibilla A, "Pioglitazone and Metformin fixeddose combination in type 2 diabetes mellitus: an evidencebased review of its place in therapy" Core Evid., vol. 2(3), pp. 189-198, 2007.

[3] Dunn CJ, Peters, DH, "Metformin. A review of its pharmacological properties and therapeutic use in noninsulin-dependent diabetes mellitus Drugs", vol. 49, pp. 721-749, 1995.

[4] Standards of Medical Care in Diabetes. American Diabetes Association. Diabetes Care, 34 (Suppl 1), S11-61, 2011.
[5] Defang Y, "Formulation and evaluation of bi-lay er tablets of Metformin Hcl and Glipizide", Y. Pharm. Res., vol. 16, pp.1748-1756, 2005.

[6] Giovanna C, Marzia C, Francesca M, Natascia, M., Paola, M. "Sustained release matrix tablets of metformin hydrochloride in combination with triacetyl beta cy clodextrin", Eur J Pharm Biopharm., vol. 68, pp. 303-09, 2008.

[7] Reddv. K.R. Mutalik. S.. Reddv. S.. "Once-dailv sustained release matrix tablets of Nicorandil: Formulation and in vitro evaluation", AAPS PharmSciTech., vol. 4(4), pp. 1-9, 2003.

[8] Mohammed AD, James LF, Michael HR, John EH, RajabiSiahbhoomi AR, Release of propranolol hydrochloride from matrix tablets containing sodium carboxymethy lcellulose and hy droxypropy lmethy lcellulose", Pharm. Dev. Tech., vol. 4, pp. 313-324, 1999.

[9] Banker, G. S., Anderson N. R. The Theory and Practice of Industrial Pharmacy, Philadelphia, pp. 317-8, 1987.

[10] Indian Pharmacopoeia. The Controller of Publications, Delhi, vol. 2, pp. 734-6, 1996.

[11] Higuchi T, "Mechanism of sustained action medication. Theoretical analy sis of rate of release of solid drugs dispersed in solid matrices", J. Pharm. Sci., vol. 52, pp. 1145-1149, 1963.

[12] Korsmeyer RW, Peppa NA, "Controlled release delivery systems”, Dekker, New York, pp. 77-101, 1983.

[13] Beckett AH, Behrendt WA, Hadzija BW, "Bioavailability of controlled-release metoclopramide. 2nd communication: multiple dose study", Arzneimettelforschung, vol. 37, pp. 221-224, 1987. 